Classification

Physics Abstracts

$66.30-81.40-82.65$

\title{
Integranular segregation of sulfur in nickel due to a flux of quenched-in vacancies
}

\author{
F. Ferhat, G. Saindrenan and D. Roptin \\ E.N.S.M., 1 rue de la Noé, 44072 Nantes Cedex 03, France
}

(Reçu le 24 août 1989, accepté le 23 novembre 1989)

\begin{abstract}
Résumé. - Nous avons étudié la ségrégation intergranulaire du soufre dans le nickel trempé ; ce phénomène, résultant d'un retour à l'équilibre du métal contenant à l'origine des défauts de trempe, provoque une fragilité intergranulaire limitée à environ $250 \mu \mathrm{m}$ sous la surface. Contrairement aux effets de la ségrégation d'équilibre du soufre, le nickel garde sa capacité de déformation, alors que la contrainte à la rupture chute d'autant plus que le recuit est effectué à température élevée. A partir des observations effectuées au MEB, nous avons calculé la concentration intergranulaire du soufre dans la zone fragile et son coefficient de diffusion en présence des défauts de trempe. La valeur obtenue est voisine de celle calculée à partir des résultats obtenus en surface par spectrométrie Auger sur le même matériau.
\end{abstract}

\begin{abstract}
We studied intergranular segregation of sulfur in quenched nickel ; this phenomenon caused by a return to equilibrium of the metal containing thermal vacancies, results in an intergranular brittleness of the region beneath the surface $(250 \mu \mathrm{m})$. In opposition to the effects of equilibrium segregation of sulfur, nickel presents a maximum deformation capacity while the failure stress drops so much more the temperature annealing is high. From SEM observations, we calculated the sulfur intergranular concentration in the brittle regions and its diffusion constant in the presence of thermal vacancies. This last value conforms with the value extracted from AES sulfur superficial segregation studies on the same material.
\end{abstract}

\section{Introduction.}

Interfacial segregation refers to chemical composition changes (enrichments) at free surfaces and grain boundaries relative to the nominal composition of the material. These enrichments can lead to concentrations on the order of ten thousand times [1] higher than the nominal concentration. Different processes can lead to these enrichments ; usually the term " equilibrium process" is used when segregation is essentially governed by the diffusion con-

equilibrium process » when solute is dragged through the metal by a flow of defects whose concentration is in excess of that for thermodynamic equilibrium. This excess of defects can be produced by procedures such as quenching, irradiation or plastic deformation.

The segregation phenomenon is a general one ; even in a pure metal the residual impurity contents, as low as they are, can generate the phenomenon.

Free surface segregation models are derived from the Gibbs adsorption equation [2] and attribute the driving force for the segregation to the interfacial tension. By analogy with adsorption and considering or not interactions between segregated atoms, equations similar to the Langmuir [3] or Fowler [4] adsorption isotherms account for the thermodynamic aspects of surface segregation.

Free surface segregation is not basically different from interface segregations in the bulk of the metal. However, in the case of an internal interface (grain boundary) only segregation mechanisms can oper, is no possi e. ermo ynamic models developped for grain boundary segregation (Mac Lean [5] and Guttmann [6]) lead to results similar to those achieved by the statistical approach of Lagues [7] in the case of free surface segregation. Mac Lean's model [5] explains the results with no interaction (ideal solution) and Guttmann's model [6] takes into account interactions between atoms as in the regular solution model. The isotherms obtained by these authors are then the analogs of the «classic» adsorption isotherms of Langmuir and Fowler (binary systems). So, apparently a strong 
similarity exists between free surface and bulk interface segregations in pure materials.

A free surface and grain boundary segregation study of sulfur in different grades of nickel performed by Larere [8] has provided the following kinetic and thermodynamic results :

- kinetics of surface and grain boundary sulfur segregation are proportional to the square root of the time, in agreement with the Mac Lean's model [5] ;

- although we would theoretically expect the kinetics at the grain boundary to be double those observed at the surface, experimentally they were observed to be identical. The author ascribes this fact to lattice defects generated by the surface preparation (polishing) in the close underlaying bulk ;

- values of the free enthalpies of sulfur segregation at these interfaces are in good agreement with Fowler's formalism [9], for both the grain boundary and free surface. Superficial segregation is however more stable than grain boundary segregation, and $\Delta G^{\mathrm{j}}$ depends on the grain boundary orientation;

- the maximum sulfur concentration at the grain boundary is equivalent to that for the free surface (45\% at.). This fact can be explained by assuming that the interface concentration is limited by the number of available sites ;

- the 2D compounds identified by Oudar [10] at the surface were never observed at grain boundaries, although they probably do exist [6].

Aside from these difference, there is a great similarity, qualitatively at least, between free surface and grain boundary sulfur segregation in nickel. Therefore, we can use results on surface segregation obtained with one of the numerous existing analysis method (AES, ESCA, ...) to anticipate grain boundary sulfur segregation in nickel.

Another difference, not mentioned above, lies in the deterioration of the mechanical properties of polycrystalline material. In the case of nickel, sulfur segregation creates grain boundary brittleness detectable by a routine tensile test. There is no basis for asserting that surface mechanical properties are not affected but due to the macroscopic nature of a tensile test no change is apparent. Brittleness then remains essentially a grain boundary property which in fact, was used historically to characterize grain boundary segregation ; it even allows the phenomenon to be quantified [11], at least in the case of equilibrium sulfur segregation in nickel.

When segregation results from a non-equilibrium process, it can be supposed that the grain boundary properties of nickel are modified in the same way as when enrichment comes from equilibrium segregation.

In this paper, free surface sulfur segregation in nickel, resulting from a non-equilibrium mechanism (supersaturation of vacancies) is compared with grain boundary properties inferred from typical features of tensile tests performed on the same material.

\section{Review of grain boundary segregation kinetic.}

The thermodynamic equation of grain boundary segregation developed by Mac Lean shows that segregation (solute grain boundary concentration) increases when the temperature is reduced, for a given binary system and bulk concentration. As this equation only describes the final state of the system without considering the kinetic parameters, it assumes an atomic flow towards the boundary; this flow depends on the solute heterodiffusion constant in the matrix. Assigning $D_{\mathrm{v}}$ as the bulk heterodiffusion constant of the solute in the lattice, the grain boundary concentration $C_{\mathrm{j}}(t)$ at the time $t$, in isothermal conditions is written, according to the simplified Mac Lean law as :

$$
C_{\mathrm{j}}(t)=\frac{4 C_{\mathrm{v}} \sqrt{D_{\mathrm{v}} t}}{\sqrt{\pi d}}
$$

where $C_{\mathrm{v}}$ represents the bulk solute concentration and $d$ the grain boundary thickness. To be used, this equation assumes certain conditions to be satisfied ; this problem has been frequently discussed (see [12] for example).

Grain boundary segregation can be modified by the action of point defects. Studies published by Aust et al. [13] concerning a lead bicrystal purified by a zone refining process, annealed in a salt bath, then cooled in air, show that the region close to grain boundary is less hard than the rest of the grain. This result can be explain by the preferential elimination into the boundary of vacancies and vacancy clusters from the region close to the boundary. On the other hand, when the lead contains additions (solutes) such as tin or gold, an increase in the hardness in the vicinity of the grain boundary is observed. This phenomenon is characterized by an increase in hardness with increasing quenching temperature and quenching rate; it affects a zone several microns wide adjacent to the boundary. According to the authors, the phenomenon is explained by formation of vacancy-solute atom complexes during annealing. When the material is quenched in air, complexes migrate towards boundaries and dissociate in their vicinity; vacancies vanish in the boundaries leaving clusters of solute atoms. This explanation assumes an attractive interaction of vacancies with solute atoms. In the case repulsive or no interaction between solute atoms and vacancies, the metal may behave as a pure one. The authors confirm this point on zinc, tin and lead purified by zone refining and 
containing different solutes such as gold, copper, aluminium and calcium.

Recently, an A.E.S. study of surface sulfur segregation [14] performed on nickel 270, vacuum annealed at $1150{ }^{\circ} \mathrm{C}$ and rapidly quenched in cold water, revealed values of sulfur diffusion constants substantially higher than values extrapolated from literature data (Tab. I). These results are interpreted according to Aust's model : during high temperature annealing, vacancy-sulfur complexes are created and trapped in the metal by quenching. A subsequent annealing induces supersaturated vacancies to be eliminate at vacancy sinks (grain boundaries, free surface and dislocations). Vacancy elimination occurs by migration of complexes. Near the free surface, these complexes are split up: vacancies vanish at the surface while sulfur atoms remain in its vicinity. Thus, the sulfur concentration is increased near the surface, this can lead to segregation subsequent to the actual vacancy elimination stage.

Table I. - Diffusion constant ratio of sulfur in quenched nickel and annealed nickel.

\begin{tabular}{|c|c|c|c|}
\hline Temperature & 500 & 600 & 700 \\
\hline$\left(D^{\prime} / D_{\mathrm{v}}\right)_{\mathrm{S}}^{\mathrm{Ni}}$ & $10^{4}$ & $10^{3}$ & $5 \times 10^{2}$ \\
\hline
\end{tabular}

Based on the analogical behavior at free surface and grain boundaries and assuming similar sulfur segregation kinetics at the two types of interfaces, intergranular brittleness, detectable by tensile testing, can be expected in nickel.

\section{Brittleness-segregation correlation.}

For pure nickel, brittleness is an essentially intergranular property that Larere [11] used to characterize sulfur segregation. This brittleness is evidenced by the loss of the ability of nickel to suffer elongation, since the domain of plastic deformation totally disappears when the brittleness is highest. Tensile strength $\sigma_{\mathrm{m}}$, becomes nearly equal to the $0.2 \%$ proof stress of nickel measured with no intergranular se re ation 11 . Thus, the correlation between brittleness and intergranular sulfur segregation can be expressed by an expression $\sigma_{\mathrm{m}} f\left(C_{\mathrm{j}}\right)$. This correlation, established experimentally at $77 \mathrm{~K}$, for nickel with $5 \mathrm{wt}$ ppm sulfur is given by :

$$
\sigma_{\mathrm{m}}(\mathrm{MPa})=700-1450 C_{\mathrm{j}} .
$$

This correlation allowed the author to evaluate the free enthalpy of sulfur intergranular segregation in nickel according to the Fowler formalism. Since the brittleness is so much more apparent when the deformation temperature is low, deformation is frequently performed at boiling nitrogen temperature $(77 \mathrm{~K})$.

\section{Material and experimental procedure.}

The material used is 270 grade nickel (Wiggin alloys) produced by sintering ex-carbonyl derived powder. Purity is higher than $99.98 \%$; table II gives the concentrations of the principal impurities.

Table II. - Chemical analysis of 270 nickel.

\begin{tabular}{|c|c|c|c|c|c|c|}
\hline Impurity & Fe & Mn & C & O & S & $\Sigma$ others \\
\hline Content (ppm) Wt & 30 & 20 & 70 & 21 & 0.5 & $\leqslant 50$ \\
\hline
\end{tabular}

The tensile specimens are flat micro-specimens with a gage length $2 \mathrm{~mm}$ wide and a thickness of $1 \mathrm{~mm}$ or $0.5 \mathrm{~mm}$, die cut from cold rolled sheet. Tensile specimens are annealed at $1150{ }^{\circ} \mathrm{C}$ in evacuated quartz capsules under a residual atmosphere of pure N 55 argon for one hour, then cold water quenched. Before sealing, $\mathrm{TiZr}$ strips are heated in the capsule in order to trapp the residual oxygen. Such a procedure leads to very low oxygen partial pressure during annealing. At the quenching temperature, the equilibrium vacancy concentration is about $2 \mathrm{ppm}$ [15], the same order of magnitude as the sulfur concentration; this value is calculated neglecting the effects of vacancy-sulfur atom interaction. This interaction exists as it can be seen further ; its effect at high temperature results in increasing the vacancy concentration at equilibrium. Therefore, the value of the interaction energy between a sulfur atom and a vacancy in nickel is not yet well established. In a previous paper [14], we proposed $-1.5 \mathrm{eV}$ as a value extracted from kinetic of superficiel segregation of sulfur. Although similar values have been determined for vacancy-sulfur interaction in iron [16], it seems high in comparison with the nickel sulfide $\mathrm{Ni}_{3} \mathrm{~S}_{2}$ enthalpy formation : $-1.7 \mathrm{eV}$. Because of this doubt and also because the experimental results do not depend, in first approximation, on the exact value of the vacancy concentration, we have neglected the influence of interacion on $t$ e equi 1 rum vacancy concentration at the quenching temperature. Segregation annealings after quenching are identical (temperature and time) to ones which allowed the observation of free surface segregation [14] (Tab. III). Tensile tests are performed with an ADAMEL DY 25-20 machine; the strain rate is $10^{-3} \mathrm{~s}^{-1}$. The specimens are immersed in boiling nitrogen. Values of the true tensile stress at failure $\sigma_{m}$, and of the rational strain before necking are calculated from the experimental loadelongation curves. Fracture surface features are examined by SEM. 
Table III. - Annealing conditions of the specimens after quenching.

\begin{tabular}{|c|r|r|r|r|c|}
\hline $\mathrm{N}^{\circ}$ sample & 1 & 2 & 3 & 4 & 5 \\
\hline $\begin{array}{c}\text { Annealing } \\
\text { temperatures }\end{array}$ & 450 & 500 & 600 & 700 & 750 \\
\hline $\begin{array}{c}\text { Annealing } \\
\text { times (min) }\end{array}$ & 120 & 160 & 100 & 200 & 120 \\
\hline$\sqrt{D t}(\mu \mathrm{m})$ & 1.8 & 5.12 & 11.5 & 40 & 71 \\
\hline
\end{tabular}

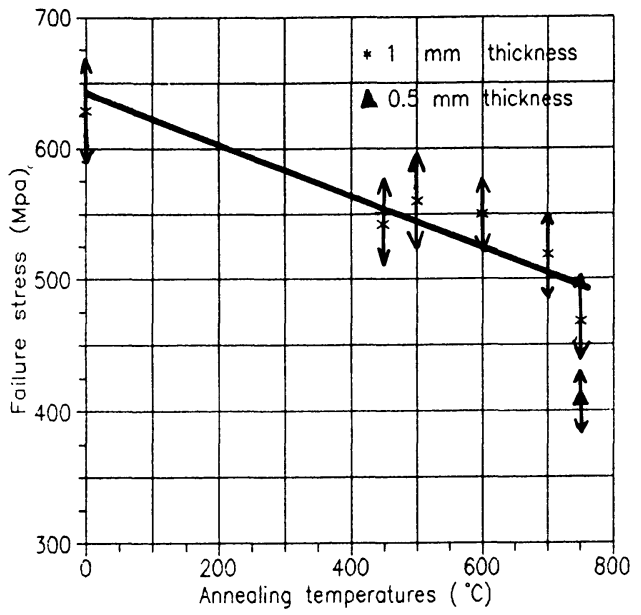

(a)

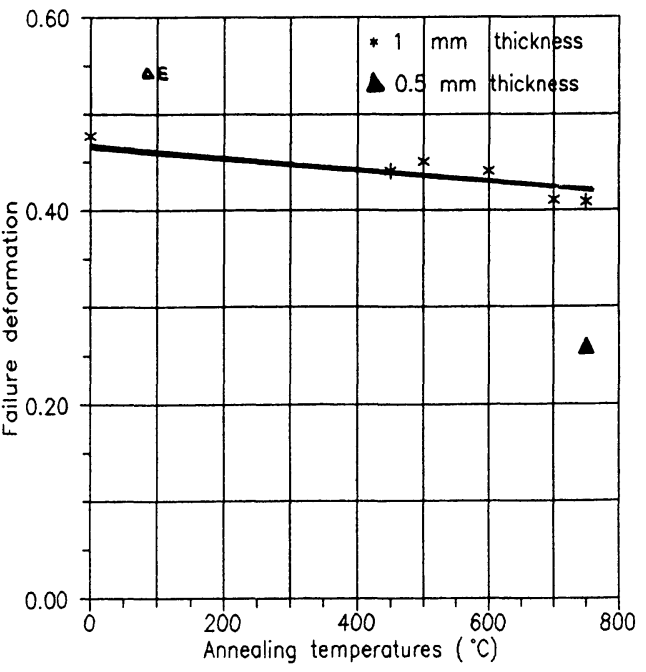

(b)

\section{Experimental results and discussion.}

The results of the tensile tests carried out on specimens quenched from $1150{ }^{\circ} \mathrm{C}$ and annealed according to the data of table 3 are reported in figures 1 and 2 . In figure 1 are reported the values of failure stress $\sigma_{\mathrm{m}}$ and deformation $\varepsilon_{\mathrm{m}}$ versus temperature. Because the annealing times are not identical, in figure 2 are reported the same parameters versus $\sqrt{D t}$, where $t$ is the annealing time and $D$ is the diffusion constant of sulfur in quenched nickel. We can see that $\sigma_{\mathrm{m}}$ decreases as $\sqrt{D t}$ (i.e. the annealing temperature) increases ; on the other hand, $\varepsilon_{\mathrm{m}}$ does not vary significantly with the annealing temperature. This result is surprising since the brittleness is evidenced mainly by effect on the ability to undergo deformation. In comparison, the tensile test results

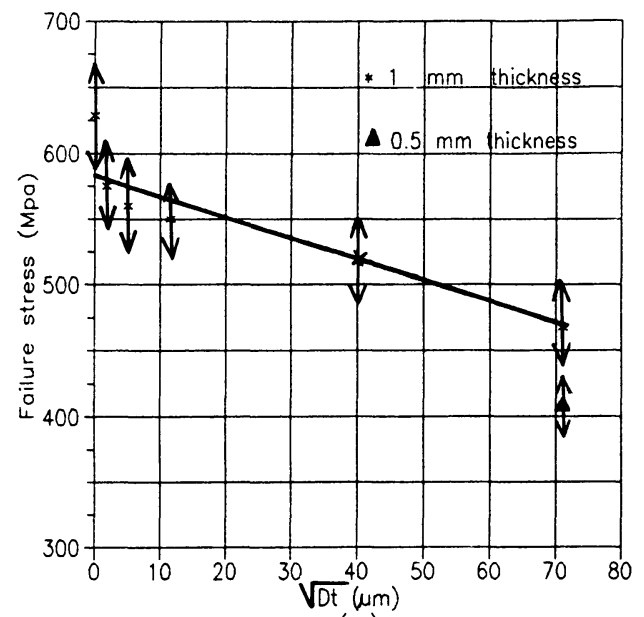

(a)

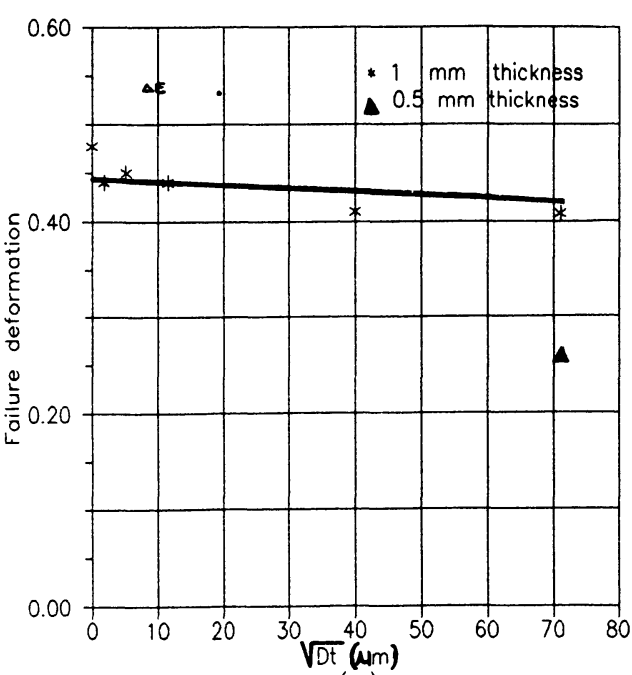

(b)

Fig. 2. - Variation of failure stress (a) and failure strain (b), versus $\sqrt{D . t}$, (deformation temperature : $77 \mathrm{~K}$ ).
Fig. 1. - Variation of failure stress (a) and failure strain (b), versus annealing temperature, (deformation temperature : $77 \mathrm{~K})$. 
published by Larere [11] relative to nickel containing 5 wt. ppm of sulfur, annealed at $625^{\circ} \mathrm{C}$ show that the maximum brittleness is obtained for a 13 days annealing time ; this brittleness is shown by a regular decrease in the failure stress as well as in the deformation.

This difference in the mechanical behaviour of nickel depending on the nature of segregation mechanism is confirmed by the SEM observations of the fracture surfaces. Figure 3 a presents micrographs of the fracture surface of the specimen annealed 120 minutes at $750{ }^{\circ} \mathrm{C}$ after quenching ; we observe a complex morphology: the core of the specimen (mark B) presents a ductile aspect while the external regions (mark A) present a brittle one. Such a morphology observed more or less on all specimens annealed after quenching explains the tensile test results. The deformation of a'metal is independent of the specimen area; as long as ductile metal remains in the core of the specimen there is no noticeable decrease in the deformation capacity. On the other hand, failure stress is reduced as the brittle area is extended in the specimen section. It seems that the origin of this complex feature must come from the thermokinetic properties of the nickel; indeed, specimen cooling during water quenching supposes a thermal flux from the core to the free surface. This flux depends on the thermal conductivity of nickel ; the cooling rate likely varies versus the depth under the surface resulting in a different efficiency of thermal vacancy trapping. In the core, the metal does not retain non-equilibrium vacancies and then the dynamic segregation of sulfur through the vacancy mechanism as described in a prior paper [14] does not appear. On the other hand, near the surface, the cooling rate is high enough to retain supersaturated vacancies which will be eliminated during the later annealing. This in turn provokes the interfacial sulfur segregation (to the free surface and grain boundaries). The transition between the ductile and brittle areas is abrupt (see photos in Fig. 3), while it seems that the cooling rate should have a continuous variation. We have verified indirectly the hypothesis of vacancy non-trapping in the core of the specimen with a tensile test carried out on a thinner specimen $(0.5 \mathrm{~mm}$ instead of $1 \mathrm{~mm})$. After water quenchıng from $1150{ }^{\circ} \mathrm{C}$ and annealing $120 \mathrm{~min}$ at $750{ }^{\circ} \mathrm{C}$ (the anneal yielding the lowest failure stress), we observe a drop in the failure stress and shift in the deformation capacity relative to quenched nickel (about $50 \%$ Fig. 1). The fracture surface features are shown in the photos of figure 4 . In this figure we can see that the ductile part has nearly disappeared; there remains in the specimen core some zones with ductile feature (mark $B$ in photo 4a), but the fracture surface is mainly brittle. Such a variation of the morphology of the fracture features with the specimen thickness can be explain only by a modifi-

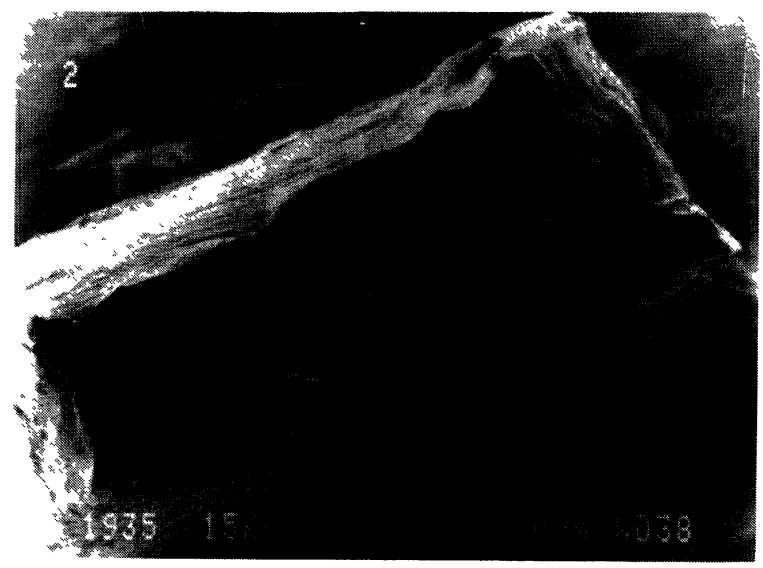

(a)

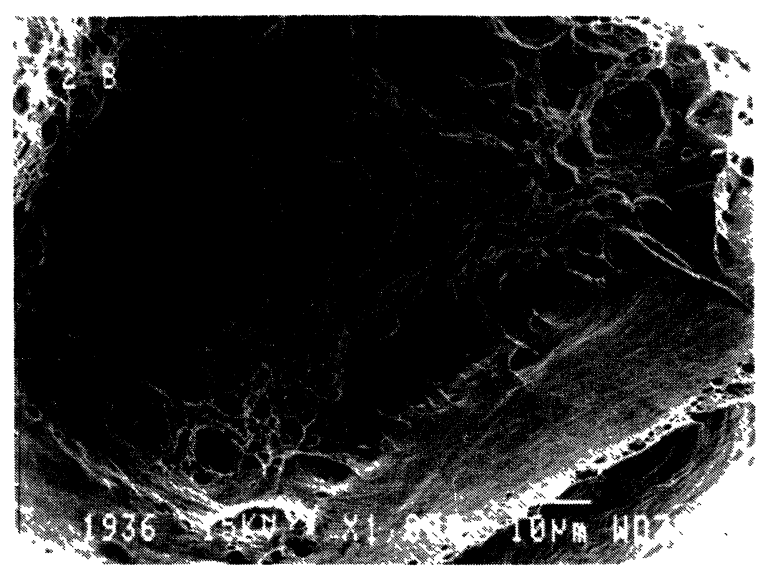

(b)

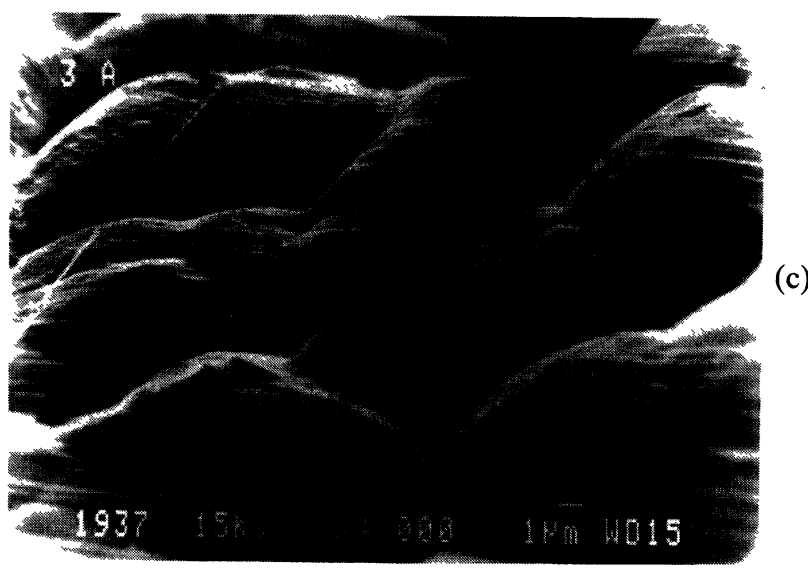

Fig. 3. - Fracture feature surface of the tensile sample $1 \mathrm{~mm}$ thickness.

cation of the cooling rate, i.e. the trapping of vacancies, beyond a certain depth; in the present case, the thickness of efficient trapping of vacancies is roughly $0.25 \mathrm{~mm}$ beneath the surface.

Although we observe almost no ductile regions on the fracture surface of the $0.5 \mathrm{~mm}$ thick specimen, the brittleness is less than that reached after equilibrium segregation annealings. Larere [8] observed a complete disappearance of the plastic regime in 


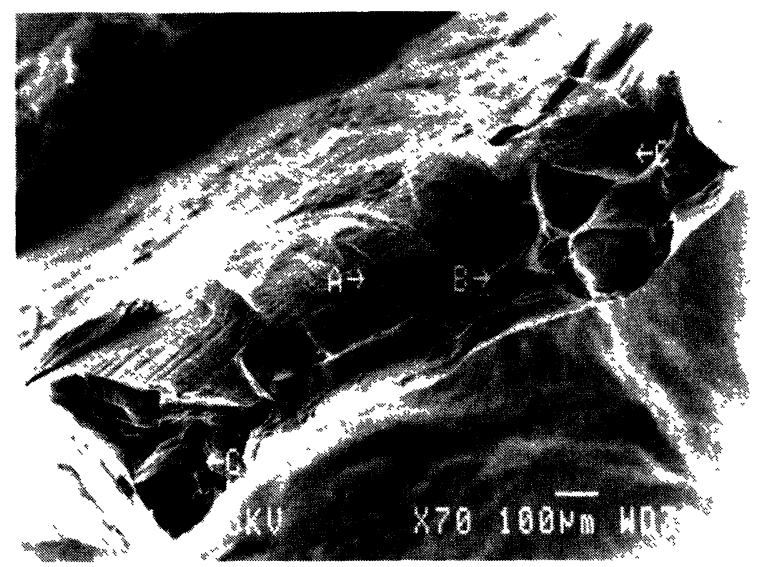

(a)
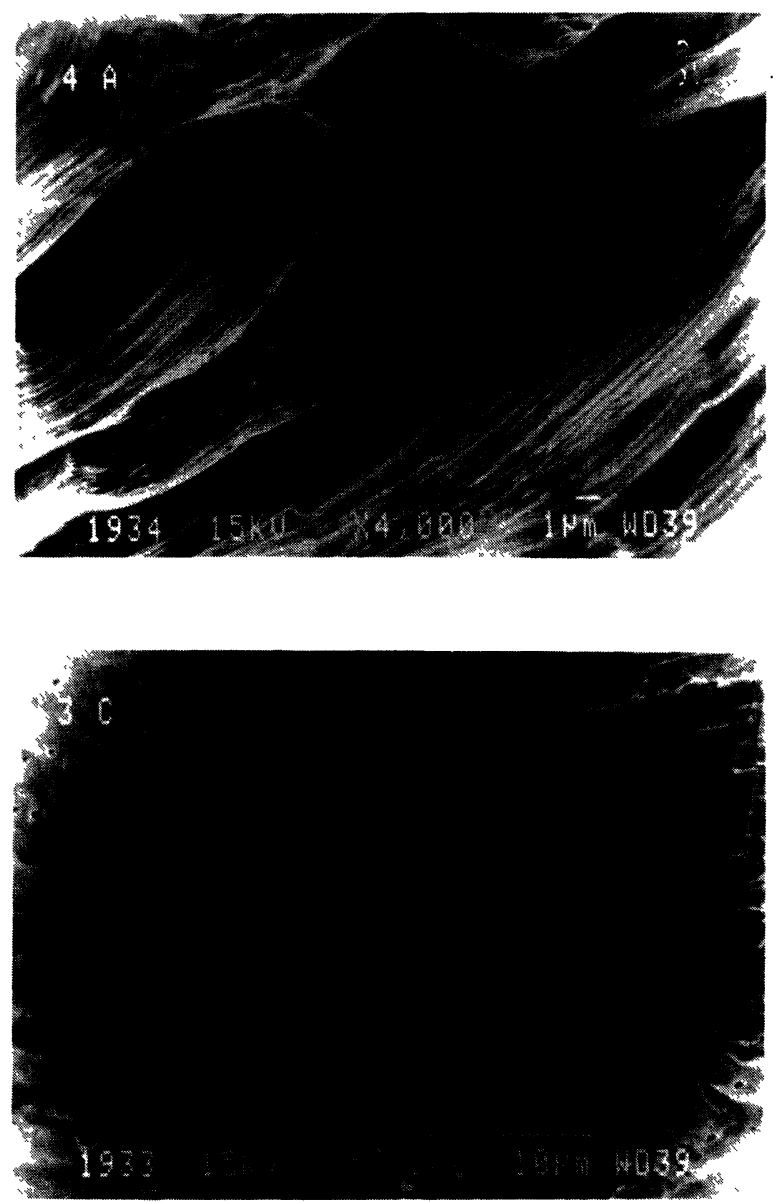

Fig. 4. - Fracture feature surface of the tensile sample $0.5 \mathrm{~mm}$ thickness.

nickel $\left(\sigma_{\mathrm{m}} \approx \sigma_{0.2}\right.$ and $\varepsilon \approx 0$ ) following a segregation anneal at $625^{\circ} \mathrm{C}$ for 13 days. Beyond this time, he observed a recovery of the deformation capacity and of the failure stress to values similar to the initial ones. He attributed this recovery to conversion of intergranular segregation into intergranular precipitation of sulfides. In the present case it can be supposed that intergranular microprecipitation is concomittant to segregation resulting in a limitation of the consequences of this latter phenomenon.

Because of its complex fracture surface morphology, we will treat these specimens as a composite material : a ductile core surrounded by a brittle external region. We can then express the failure stress as

$$
\sigma_{\mathrm{m}}=V_{\mathrm{d}} \sigma_{\mathrm{d}}+V_{\mathrm{b}} \sigma_{\mathrm{b}}
$$

with

$\sigma_{m}$ : experimental value of failure stress,

$\sigma_{\mathrm{d}}$ : failure stress of the ductile part of the specimen; we choose its value as the non-annealed nickel failure stress,

$\sigma_{\mathrm{b}}$ : failure stress of the brittle part of the specimen, $V_{\mathrm{d}}$ : volume fraction of the ductile part, $V_{\mathrm{b}}$ : volume fraction of the brittle part.

The volume fractions are assumed to be equal to the area fractions measured on the photos.

From this relation, we can calculate $\sigma_{\mathrm{b}}$. For the (b) specimen annealed at $750{ }^{\circ} \mathrm{C}$ we have :

$$
\begin{aligned}
\sigma_{\mathrm{m}} & =465 \mathrm{MPa} \\
\sigma_{\mathrm{d}} & =630 \mathrm{MPa} \\
S_{\mathrm{d}} & =0.35 \\
S_{\mathrm{b}} & =0.65 \\
\sigma_{\mathrm{b}} & =376 \mathrm{MPa} .
\end{aligned}
$$

Then

From relation (2), we can calculate the intergranular sulfur concentration in the brittle nickel and we find

$$
C_{\mathrm{j}}=0.23
$$

From this value and assuming a kinetic law similar to Mac Lean's we calculate an apparent diffusion (c) constant $D_{\mathrm{v}}=1.3 \times 10^{-8} \mathrm{~cm}^{2} \mathrm{~s}^{-1}$; this value is quite close to the one extracted from surface segregation measurements on the same specimen: $0.7 \times 10^{-8} \mathrm{~cm}^{2} \mathrm{~s}^{-1}[14]$.

\section{Conclusions.}

1) The return to equilibrium of quenched nickel provokes intergranular segregation of sulfur as well as superficial segregation. The apparent diffusion constant of sulfur extracted from tensile test results is quite close to found for the case of superficial segregation.

2) Due to this segregation, we observe an intergranular mechanical damage similar to that observed after an equilibrium segregation treatment.

3) This non-equilibrium segregation is dependent upon a vacancy flux and intergranular brittleness is observed only in the regions of nickel where the thermal vacancies are trapped. These effects are 
observed only in grain boundaries within $250 \mu \mathrm{m}$ of the surface under our experimental conditions.

4) The mechanical behaviour of nickel results from the thermokinetic properties of the metal; this point is the subject of further studies.

5) We have never observed a total brittleness of nickel. This may result from partial conversion of the intergranular segregation into intergranular precipitation of sulfur.

\section{Acknowledgments.}

The authors acknowledge the technical assistance of J. P. Roche for Auger Electron Analysis.

\section{References}

[1] Larere A., Guttmann M., Dumoulin P., Roques-Carmes C., Act. Met. 30 (1982) 30685.

[2] Moya F., Moya-Gontier G. E., Phys. Status Solidi a 2 (1970) 101.

[3] Langmuir I., J. Am. Chem. Soc. 40 (1918) 1371.

[4] Fowler R. H. and Guggenheim E. A., Proc. Roy. Soc. A 145 (1934) 699.

[5] MaC Lean D., Grain Boundaries in Metals (Clarendon Press) 1957, p. 116.

[6] Guttmann M., Met. Trans 8A (1977) 1383.

[7] Lagues M., Thèse de Doctorat d'état, Univ. Paris XI (1974).

[8] Larere A., Thèse de Doctorat d'état, Univ. Paris XI (1983) p. 268.
[9] Fowler R. H., Proc. Cambridge Phil. Soc. 31 (1935) 260.

[10] Oudar J., Mat. Sci. Eng. 42 (1980) 101.

[11] Larere A., Thèse de Doctorat d'état, Univ. Paris XI (1983) p. 135.

[12] Lea C., Seah M. P., Philos. Mag. 35 (1977) 213.

[13] Aust K. T., Hanneman R. R., Niessen P. and Westbrook, J. H., Act. Met. 16 (1968) 291.

[14] Ferhat F., Roptin D., Saindrenan G., Script. Met. 22 (1988) 223.

[15] WyCisK W., Feller-KNiEPMEIER M., J. Nucl. Mater. 69 et 70 (1978) 616.

[16] Faulkner R. G., Private Communication. 